
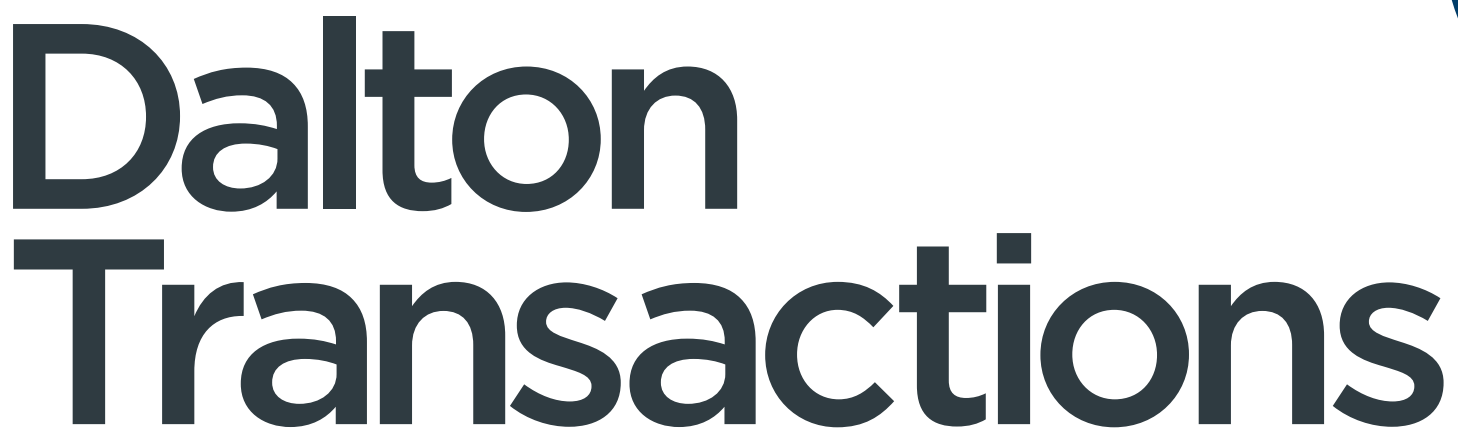

An international journal of inorganic chemistry

rsc.li/dalton

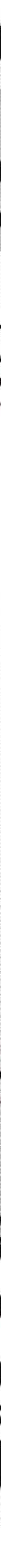




\section{A) Check for updates}

Cite this: Dalton Trans., 2020, 49, 9965

\title{
Tris(ferrocenylmethidene)sumanene: synthesis, photophysical properties and applications for efficient caesium cation recognition in water $\dagger$
}

\author{
Artur Kasprzak, (DD *a Agata Kowalczyk, (DD b Agata Jagielska, (DD ${ }^{\mathrm{c}}$ Barbara Wagner, (DD c \\ Anna M. Nowicka (D) ${ }^{b}$ and Hidehiro Sakurai (D) ${ }^{d}$
}

Received 24th April 2020, Accepted 15th June 2020

DOI: $10.1039 / \mathrm{d} 0 \mathrm{dt} 01506 \mathrm{~g}$

rsc.li/dalton

\begin{abstract}
The synthesis of a sumanene derivative bearing three ferrocenyl substituents is presented. This conjugated compound is solution-processable, shows red-light emission with high fluorescence quantum yield and can be used for the construction of the first buckybowl-based sensor for the selective and effective recognition of caesium cations $\left(\mathrm{Cs}^{+}\right)$in aqueous solution.
\end{abstract}

Ferrocene $(\mathrm{Fc})$ is a metallocene with various applications. ${ }^{1} \mathrm{Fc}$ is a good candidate for the construction of redox sensors and acts as a reference system in voltammetric measurements. ${ }^{2} \mathrm{Fc}-$ bearing systems are chemically inert, electrochemically and thermally stable, and dissolve well in a wide range of solvents, and their redox processes are reversible and single-electron in nature and have a high electron transfer rate. The redox properties of Fc originate from the presence of a ferrocene/ferrocenium cation $\left(\mathrm{Fc} / \mathrm{Fc}^{+}\right)$couple. Ferrocene derivatives having an aryl substituent are of great interest for the design of functional molecules with tuned red-ox properties. For instance, the reports deal with the applications of Fc-pyrene ${ }^{3}$ or Fc-porphyrin $^{4}$ probes for the electrochemical detection of ions. Interestingly, a study on the synthesis of conjugated Fc oligomers bearing several metallocene units, was also reported. ${ }^{5}$ Such oligomers exhibited intriguing interactions between redox sites. In fact, the electrochemical profile of Fc-bearing materials strongly depends on the compound structure, e.g., its symmetry, distance between Fc residues and their electronic communication. ${ }^{1,2}$

Sumanene (1), a fullerene fragment, belongs to the class of the so-called buckybowls featuring a bowl-shaped motif (Fig. 1a). ${ }^{6}$ This molecule is a promising candidate for the

\footnotetext{
${ }^{a}$ Faculty of Chemistry, Warsaw University of Technology, Noakowskiego Str. 3, o0-664 Warsaw, Poland. E-mail: akasprzak@ch.pw.edu.pl

${ }^{b}$ Faculty of Chemistry, University of Warsaw, Pasteura Str. 1, 02-093 Warsaw, Poland ${ }^{c}$ Biological and Chemical Research Centre, Faculty of Chemistry, University of Warsaw, Zwirki $i$ Wigury Str. 101, PL-02-093 Warsaw, Poland

${ }^{d}$ Division of Applied Chemistry Graduate School of Engineering, Osaka University, 2-1 Yamadaoka, Suita, Osaka 565-0871, Japan

$\dagger$ Electronic supplementary information (ESI) available: Experimental section, compound characterization data, and electrochemical data. See DOI: 10.1039/ D0DT01506G
}

design of functional organic materials. The unique properties of sumanene result from the presence of a curvature in its structure giving rise to unusual assembling properties or dynamic behaviours, e.g., bowl-to-bowl inversion. Recently, we have reported the synthesis of various sumanene-tethered ferrocenes $^{7}$ and the applications of selected conjugates $^{7 b}$ for caesium cation $\left(\mathrm{Cs}^{+}\right)$recognition in organic solvents. The driving force responsible for this recognition was the site-selective cation- $\pi$-interaction with the inclusion of sumanene's concave site. ${ }^{6 d, 8}$ Sumanene was found to act as a $\mathrm{Cs}^{+}$recognition material in its neutral state. It is worth noting that the detection of $\mathrm{Cs}^{+}$is of the highest environmental importance. Significant concentrations of $\mathrm{Cs}^{+}$were found in nuclear plant waste and in post-disaster areas, especially in the case of the nuclear plant accident in Fukushima in 2011. ${ }^{9}$ Importantly, from the viewpoint of public health and environmental monitoring, special attention should be paid to $\mathrm{Cs}^{+}$detection in water.

Herein, we report the synthesis of tris(ferrocenylmethidene) sumanene (3) and its photophysical and electrochemical properties. To our delight, this compound is readily soluble in many organic solvents together with very efficient red-light emission properties. What is more, electrochemical studies revealed the promising redox properties of this derivative. Encouraged by this finding, 3 was employed to construct a sensor that showed remarkably effective and selective $\mathrm{Cs}^{+}$ detection in water. This is the first example of using a buckybowl compound for the construction of a sensor and its application towards the recognition of an analyte in aqueous solution.

The synthesis of 3 was carried out starting from sumanene (1) and ferrocenecarboxaldehyde (Fc-CHO; 2) according to the reported procedure $^{10}$ which gave excellent yield (88\%; Fig. 1b). ${ }^{11}$ The combination of NMR spectroscopy, Fourier- 
a)

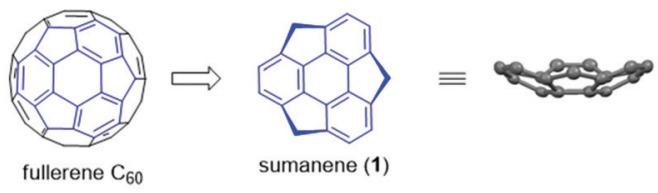

b)

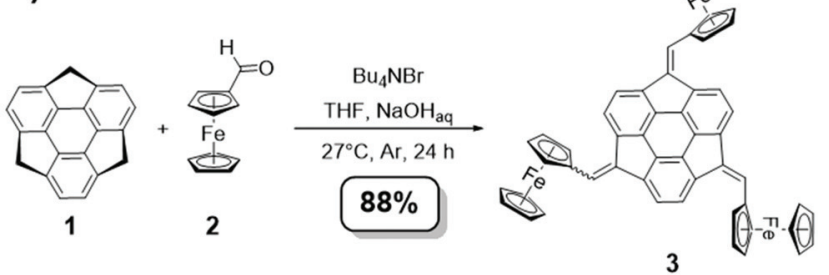

c)
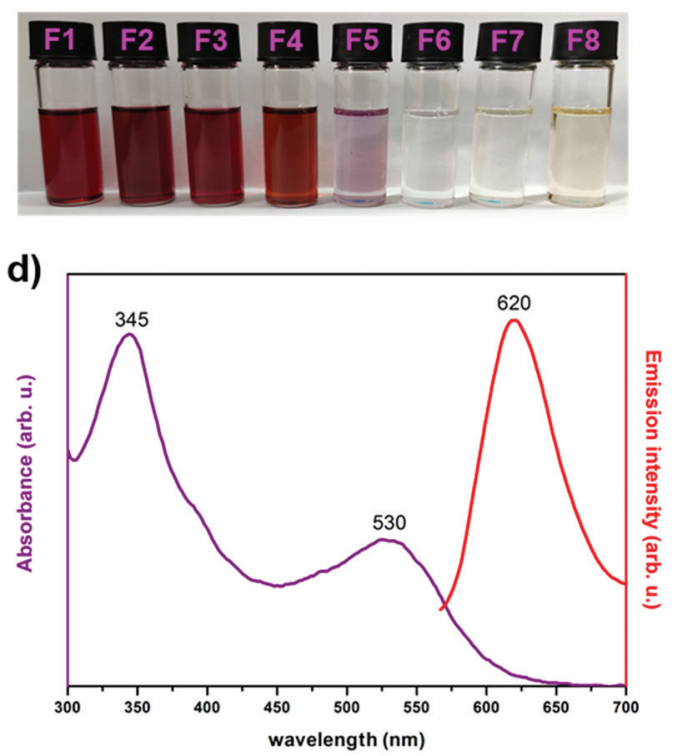

Fig. 1 (a) Structure of sumanene (1), together with the graphical representation of its crystal structure and fullerene origin; (b) synthesis of 3; (c) comparison between the solution colours $\left(2 \times 10^{-4} \mathrm{M}\right)$, from left to right: 3 in $\mathrm{CH}_{2} \mathrm{Cl}_{2}$ (F1), 3 in PhMe (F2), 3 in $\mathrm{CH}_{3} \mathrm{CN}$ (F3), fullerene $\mathrm{C}_{70}$ in $\mathrm{PhMe}$ (F4), fullerene $\mathrm{C}_{60}$ in PhMe (F5), sumanene in PhMe (F6), Fc in $\mathrm{PhMe}$ (F7), and $\mathrm{Fc}-\mathrm{CHO}$ in $\mathrm{PhMe}$ (F8); (d) absorbance (violet curve) and emission (red curve; excitation wavelength $530 \mathrm{~nm}$ ) spectra of 3 (PhMe, $\left.2 \times 10^{-5} \mathrm{M}\right)$.

transform infrared spectroscopy (FT-IR) and high-resolution mass spectrometry (HRMS) confirmed the formation of $3 .{ }^{12}$ As expected, ${ }^{10}$ the ${ }^{1} \mathrm{H}$ NMR analysis revealed the presence of diastereomers $\left(C_{3}\right.$ symmetrical and unsymmetrical).

Compound $\mathbf{3}$ was found to be air-stable both in solution and in the solid state at a significant time interval. ${ }^{13}$ In addition, 3 is solution-processable, because of its excellent solubility in many commonly used organic solvents, both polar and non-polar, including dichloromethane, chloroform, hexane, benzene, toluene, tetrahydrofuran, acetonitrile and acetone. The colour of $\mathbf{3}$ in each solvent was deep purple-red (Fig. 1c). It is noteworthy that the solutions of pristine sumanene, $\mathrm{Fc}$ and $\mathrm{Fc}-\mathrm{CHO}$ did not exhibit such optical properties.
On the other hand, the colour of 3 in solution was comparable to those of fullerenes $\left(\mathrm{C}_{70}\right.$ or $\left.\mathrm{C}_{60}\right)$. We anticipate that these features of $\mathbf{3}$ resulted from the $\pi$-conjugation. UV-Vis spectroscopy analysis revealed the absorption maxima of 3 at 345 and $530 \mathrm{~nm}$ (Fig. 1d). A red-shift was observed in comparison with similar sumanenes substituted with benzene derivatives. ${ }^{14} \mathrm{~A}$ Strong red-light emission $\left(\lambda_{\max }=620 \mathrm{~nm}\right.$; excitation wavelength $530 \mathrm{~nm}$ ) was observed for 3 (Fig. 1d). ${ }^{15}$ The fluorescence quantum yield $\left(\Phi_{\mathrm{F}}\right)$ was estimated by a relative method to be 0.81 , a very high value. ${ }^{16}$ It is worth noting that such a satisfactory $\Phi_{\mathrm{F}}$ value was not reported for pristine sumanene ( $c a$. $0.03)^{17}$ or many buckybowl-based compounds (commonly lower than 0.57). ${ }^{18} \Phi_{\mathrm{F}}$ for 3 is comparable with the respective values for highly conjugated pyrenylsumanene $(0.82)^{17 b}$ and some corannulenes bearing a push-pull architecture $(0.76$, 0.93 or 0.98$){ }^{18 g}$

Next, the cyclic voltammograms (CV) of 3 were recorded in two solvents with different dielectric constants: dichloromethane (DCM) and dimethyl sulfoxide (DMSO) at various scan rates (Fig. 2). In both solvents 3 exhibited one welldefined oxidation peak and two- or three reduction peaks. The presence of a linker between $\mathrm{Fc}$ and the benzene core resulted in more independent electrochemical properties and electron transfers. The lack of peak separation suggested a lack of electronic communication between the redox units. The Fc moi-
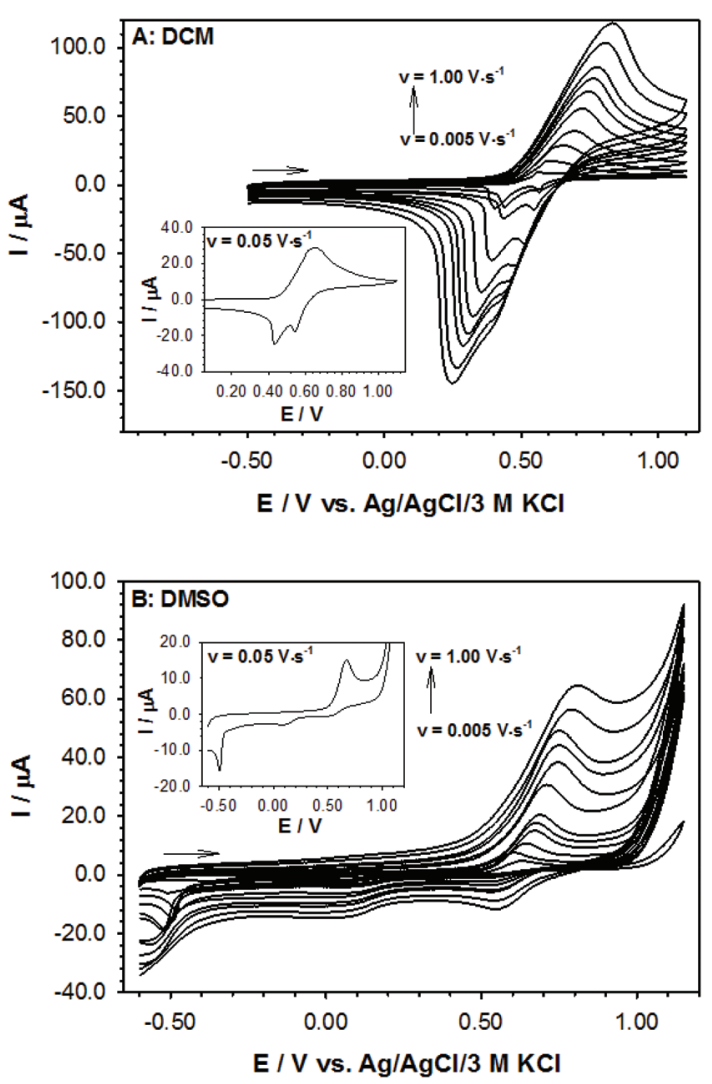

Fig. 2 Cyclic voltammograms of 3 recorded in DCM (a) and DMSO (b) at various scan rates. Experimental conditions: $C_{3}=0.77 \mathrm{mM} ; C_{\text {TBAHFP }}=$ $100 \mathrm{mM} ; T=21^{\circ} \mathrm{C}$. 
eties are electrochemically equivalent, and, thus, were oxidized at the some potential. The oxidation process of the $\mathrm{Fc}$ units leads to the formation of a positively charged product in the solution, which can interact with the solution components. DCM belongs to the solvents with a very low dielectric constant $(\sim 8.9)$. It is well known that the lower the dielectric constant of a solution, the greater the tendency to form ionic pairs with different stoichiometries. Thus, the presence of two cathodic peaks is most likely the result of the existence of ion pairs in the solution. In addition, the shape of the reduction peak (a drastic decrease in the current value, see Fig. 2a) indicates the accumulation of the oxidation product of 3 on the electrode surface. To examine if the above hypotheses were correct, we conducted additional experiments with a solvent (DMSO) characterized by a dielectric constant 5 times greater than that for DCM. The issue of product accumulation on the electrode surface has been eliminated; however, ion pairs are still formed, as evidenced by the cathodic signals of 3 (see Fig. 2b). The calculations of the diffusion coefficients of 3 were performed on the basis of the linear relationship of anodic peak current $\left(I_{\mathrm{p}}\right)$ versus square root of the scan rate $\left(v^{0.5}\right)$, because the shape of this signal indicated the clear diffusion character of the electrode process. ${ }^{19 a}$ The calculated diffusion coefficients for 3 equal to $(3.96 \pm 0.36) \times 10^{-5}$ and $(1.91 \pm 0.14) \times$ $10^{-5} \mathrm{~cm}^{2} \mathrm{~s}^{-1}$ in DCM and DMSO, respectively. ${ }^{19 b}$ For comparison, we obtained the coefficient diffusion of native Fc in DCM which is $7.72 \times 10^{-5} \mathrm{~cm}^{2} \mathrm{~s}^{-1}$. $^{20}$ The diffusion coefficient describes the diffusional transport and is an important parameter of the species that are involved in the electrochemical process. The comparable diffusion coefficient values for 3 and native Fc testify to the lack of a significant effect of sumanene on the mobility of its derivative with Fc.

We envisioned that 3 can be used for the selective recognition of $\mathrm{Cs}^{+}$. This hypothesis was based on the literature examples reporting highly specific interactions between sumanene-based molecules and $\mathrm{Cs}^{+}{ }^{6 d, 7 b}$ However, the detection of $\mathrm{Cs}^{+}$in water by buckybowl-based molecules was never studied before, despite the fact that the detection of $\mathrm{Cs}^{+}$in aqueous solutions is crucial in terms of public health and environmental monitoring. Thus, our ultimate goal in the light of this work was to design a novel probe for $\mathrm{Cs}^{+}$detection in water samples. The 3-based sensor specific versus $\mathrm{Cs}^{+}$was successfully constructed. The procedure was very simple. A droplet containing $0.77 \mathrm{mM}$ of 3 and $100 \mathrm{mM}$ of TBAHFP in DMSO was placed on the electrode surface and let to dry. After the construction step and after the interaction with $\mathrm{Cs}^{+}$, the recognition layer was also inspected using scanning electron microscopy (SEM). The obtained SEM images are presented in Fig. 3. The SEM image showed that the rather homogeneous surface experienced a significant increase of the porosity after the interaction with $\mathrm{Cs}^{+}$.

The analytical characteristics of this sensor bearing the 3based receptor $\left(\mathrm{GC} / 3-\mathrm{TBAHFP} / \mathrm{Nafion}{ }^{\circledR}\right)$ were determined on the basis of the changes in the oxidation current signal of 3 . For the preparation of the GC/3-TBAHFP/Nafion ${ }^{\circledR}$ sensor, see Section S1.5, ESI $\dagger$ and for the analytical characteristics of the

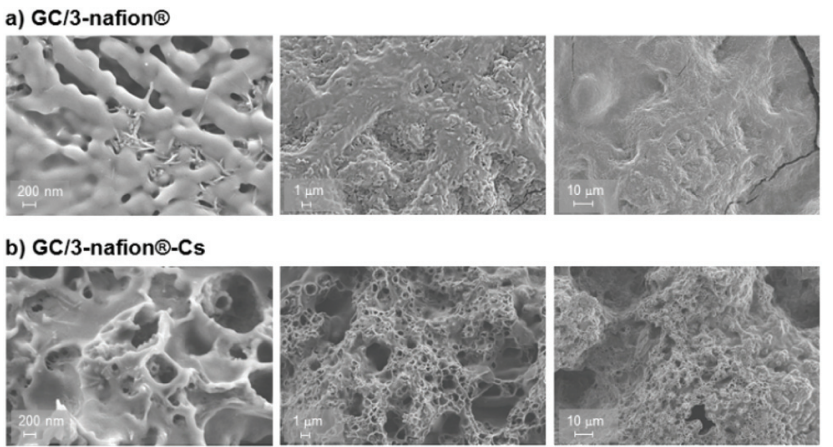

Fig. 3 SEM images of the recognition layer before (a) and after (b) interaction with $\mathrm{Cs}^{+}$.

sensor formed from the DCM solvent, see Section S8 in the ESI†.

Before the experiments with $\mathrm{Cs}^{+}$recognition the sensor was cycled between -0.5 and $1 \mathrm{~V}$ in water with tetrabutylammonium bromide (TBAB) until a stable voltammogram was obtained and voltammetrically characterised. The cyclic voltammograms of the recognition surface (Fig. 4), recorded at scan rates from 5 to $500 \mathrm{mV} \mathrm{s}^{-1}$, show well-defined oxidation and reduction peaks corresponding to the $\mathrm{Fc} / \mathrm{Fc}^{+}$redox couple. The CV redox peak currents scale linearly with the square root of the scan rate (Fig. 4, inset), indicating the semi-infinite diffusional charge transport within the redox film at these scan rates. ${ }^{21 a, b}$

The representative differential pulse voltammograms (DPV) plotted as a function of the concentration of $\mathrm{Cs}^{+}$are presented in Fig. 5a. Along with an increase in the concentration of $\mathrm{Cs}^{+}$ in aqueous solution, an increase in the current signal of the Fc unit electrooxidation was observed, see Fig. 5b. In addition, this increase in the concentration range of 1-50 $\mu \mathrm{M}$ was linear. ${ }^{21 c}$ At the concentrations of $\mathrm{Cs}^{+}$higher than $50 \mu \mathrm{M}$, the

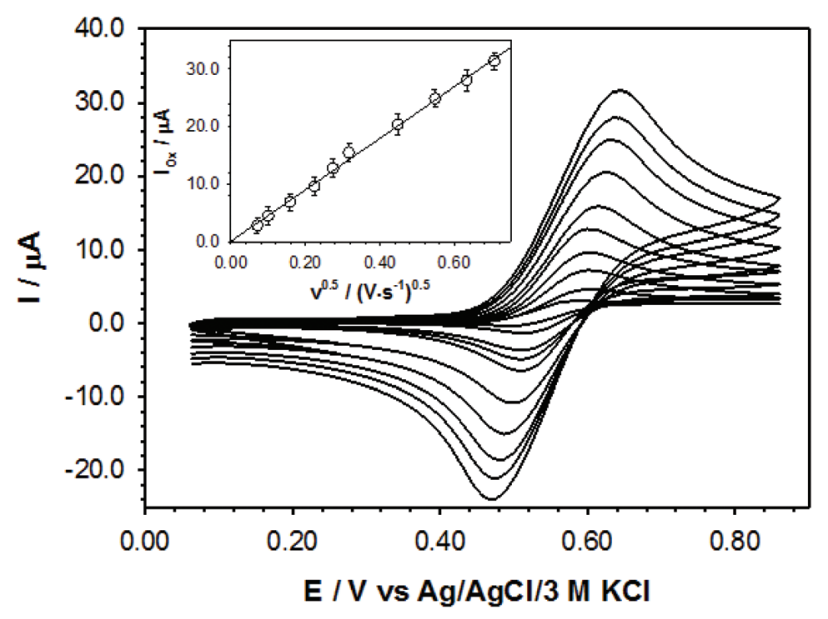

Fig. 4 Cyclic voltammograms of the recognition surface $(\mathrm{GC} / 3$ TBAHFP/Nafion ${ }^{\circledR}$ ) recorded in water with the addition of $100 \mathrm{mM}$ TBAB, at various scan rates: $5 \div 1000 \mathrm{mV} \mathrm{s}^{-1}$. Experimental conditions: potential window: $0.05 \div 0.85 \mathrm{~V}$; potential step: $0.0024 \mathrm{~V} ; T=21^{\circ} \mathrm{C}$. 
a)

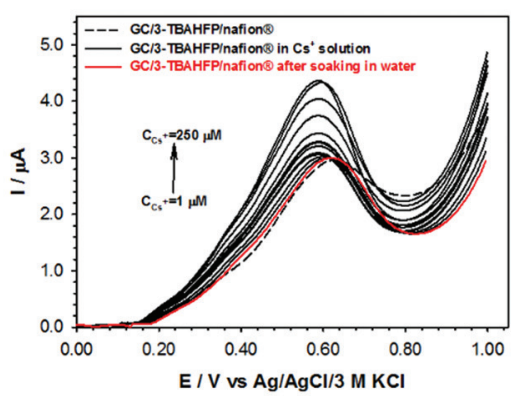

b)

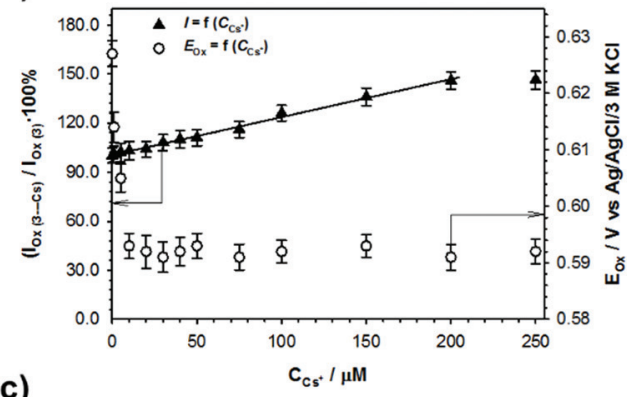

c)
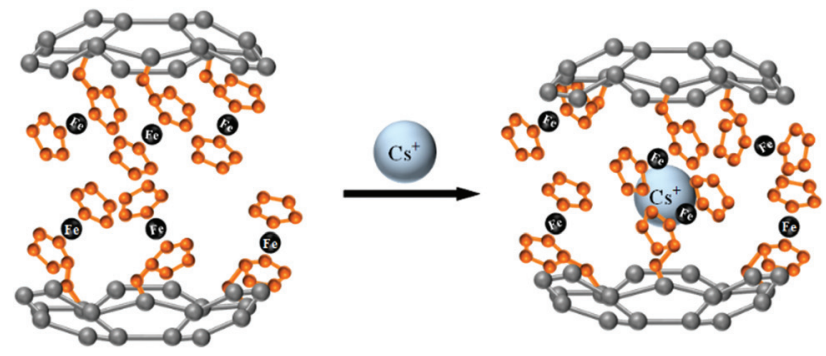

Fig. 5 (a) DPV voltammograms of GC/3-TBAHFP/Nafion ${ }^{\circledR}$ in the presence of $\mathrm{Cs}^{+}$ions in water with the addition of $100 \mathrm{mM} \mathrm{TBAB}$; (b) plots of the oxidation current and the position of the oxidation peak of $\mathrm{GC} / 3$ TBAHFP/Nafion ${ }^{\circledR}$ versus concentration of $\mathrm{Cs}^{+}$. Experimental conditions: modulation time: $0.002 \mathrm{~s}$; interval time: $0.1 \mathrm{~s}$; modulation amplitude: $0.04995 \mathrm{~V}$; step potential: $0.00495 \mathrm{~V}$; (c) graphical representation of the proposed interaction between 3 and $\mathrm{Cs}^{+}$.

changes in the intensity of the peak current were negligible. In addition, some changes in the position of the current signal were observed; the signal successfully shifted towards less positive values with increasing concentrations of $\mathrm{Cs}^{+}$in solution.

Shifting the signal towards less positive potential values indicated a simpler exchange of electrons between the electrode surface and Fc units. However, an increase in the signal intensity may point to a greater number of Fc units involved in the electrode process. Most likely, the formation of sandwich complexes between 3 and $\mathrm{Cs}^{+}$led to a rearrangement of the $\mathrm{Fc}$ units; the Fc units were closer to each other and closer to the electrode surface, making the electron exchange easier (Fig. 5c). It is known from the literature that Nafion ${ }^{\circledR}$ (fluorocarbon polymer) does not significantly limit the mobility of electrically neutral compounds; only the existence of some attractive interactions between the $\mathrm{SO}_{3}{ }^{-}$functional groups of Nafion ${ }^{\circledR}$ and specific cations might lead to the mobility restric-
Table 1 Comparison between the LOD values for various $\mathrm{Cs}^{+}$recognition materials

\begin{tabular}{lll}
\hline Material & LOD $[\mu \mathrm{M}]$ & Ref. \\
Tris(ferrocenylmethidene)sumanene & 0.02 & This work \\
Sumanenylferrocenes & $12-70$ & $7 b$ \\
Squaraine & 0.096 & $25 a$ \\
Calixarenes & $0.096-0.770$ & $25 b-d$ \\
Boron-dipyrromethene (BODIBY) & 0.273 & $25 e$ \\
Zeolite & 7.3 & $25 f$
\end{tabular}

tion. ${ }^{23}$ It is worth emphasizing that the receptor layer was constructed from a mixture consisting of compound 3 and TBAHFP in a ratio of $1: 130$. Hexafluorophosphate ions $\left(\mathrm{PF}_{6}{ }^{-}\right)$ belong to the group of strongly coordinating anions. They are therefore strongly bonded to ferrocenium cations. It is known that the ion-pairing strength of such anions with ferrocenium cations or other cations shields their positive charge, thus lowering the $E_{1 / 2}$ values of multiply charged cations. ${ }^{22}$

Compound 3 is electrically neutral; therefore, the formation of a sandwich complex with $\mathrm{Cs}^{+}$within the Nafion ${ }^{\circledR}$ polymer network is possible. The driving force for the formation of such a unique sandwich complex (Fig. 5c) shows a perfect match of $\mathrm{Cs}^{+}$with the sumanene concave cavity. The sumanene moiety remains neutral throughout the complexation; therefore, the driving force for wrapping was the site-selective cation $-\pi$ interaction between the concave face of sumanene and $\mathrm{Cs}^{+}$. The calculated limit of detection (LOD) equalled to $0.02 \mu \mathrm{M}^{24}$ This LOD value is remarkably satisfactory and is better than the respective values for the previously reported $\mathrm{Cs}^{+}$receptors (Table 1). In addition, the herein presented sensor may be potentially useful in the analyses of real samples from post-disaster areas; for example, the contamination of Mano River in Japan (north-west from the Fukishima-Daiichi plant) with active cesium $\left(\mathrm{Cs}^{137}\right)$ was reported to be $c a .0 .06 \mathrm{mM} .{ }^{9 c, 26}$

It is also worth emphasizing that the regeneration of the herein presented sensor is very easy; it can be achieved by just dipping it into water for 10 minutes and the sensor is then ready to work, see Fig. 5a. Furthermore, to prove the $\mathrm{Cs}^{+}$ selectivity, control experiments with other cations, namely $\mathrm{Na}^{+}, \mathrm{K}^{+}$and $\mathrm{Ba}^{2+}(100 \mu \mathrm{M})$, were performed. No changes in the Fc oxidation signal, and its position were observed (see Fig. 6). This means that $\mathrm{Na}^{+}, \mathrm{K}^{+}$and $\mathrm{Ba}^{2+}$ neither form complexes with 3 nor obstruct the $\mathrm{Cs}^{+}$complexation, and that the constructed GC/3-TBAHFP/Nafion ${ }^{\circledR}$ sensor is highly selective towards the $\mathrm{Cs}^{+}$recognition. High stability is a very important parameter defining the sensor's functionality. The stability of the proposed sensor was examined by measuring the changes in the value of oxidation current of the Fc units in water with $100 \mathrm{mM}$ TВAB as a function of time elapsed since the formation of the recognition layer (GC/3-TBAHFP/Nafion $\left.{ }^{\circledR}\right)$. After the preparation step, the sensor was kept under the cover at room temperature for 2 months. The proposed sensor was characterized by very good stability for the first 5 weeks. The difference in the intensities of the Fc oxidation current signal was smaller than $5 \%$. For the longer storage time ( $>5$ weeks) 


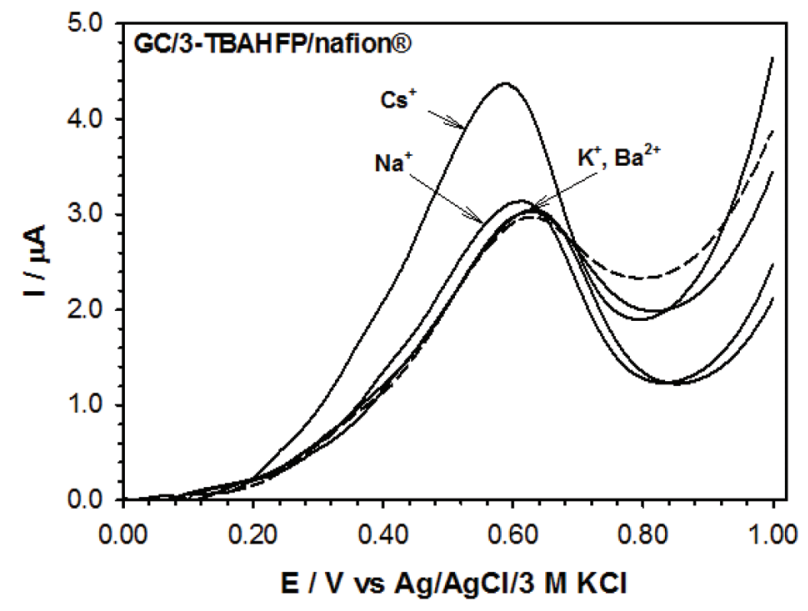

Fig. 6 DPV voltammograms of GC/3-TBAHFP/Nafion $®$ in the absence (the dashed line) and presence of different interfering cations (the solid line). Experimental conditions: modulation time: $0.002 \mathrm{~s}$; interval time: $0.1 \mathrm{~s}$; modulation amplitude: $0.04995 \mathrm{~V}$; step potential: $0.00495 \mathrm{~V}$. The recognition layer was formed from DMSO solution.

the current decreases by $10 \%$ compared to the initial value (the sensor used just after the formation of the recognition layer).

To further support the selective interaction between 3 and $\mathrm{Cs}^{+}$, UV-Vis analyses and inductively coupled plasma mass spectrometry measurements with laser ablation (LA-ICP-MS) were performed. ${ }^{27}$ The UV-Vis spectrum of 3 showed an increase in the absorbance intensity after the addition of further portions of $\mathrm{Cs}^{+}$. This feature was ascribed to the noncovalent, site-selective interaction between 3 and $\mathrm{Cs}^{+} .{ }^{7 b}$ In contrast, no changes were observed in the UV-Vis spectra of 3 measured in the presence of $\mathrm{Na}^{+}, \mathrm{K}^{+}$and $\mathrm{Ba}^{2+}$. These trends clearly elucidate the selective binding of $\mathrm{Cs}^{+}$with 3 . Job's plot analysis revealed the $2: 1$ stoichiometry of the $3: \mathrm{Cs}^{+}$system. $^{27}$ This analysis indicates the formation of anticipated sandwichtype complexes. ${ }^{7 b}$ The interactions between 3 and the selected ions: $\mathrm{Cs}^{+}, \mathrm{Na}^{+}, \mathrm{K}^{+}$, and $\mathrm{Ba}^{2+}$ were also analysed with LA-ICP-MS. In the experiments a gold substrate modified with the layer 3-TBAHFP/Nafion ${ }^{\circledR}$ was immersed in a water solution containing an appropriate anion at the $100 \mu \mathrm{M}$ level. After 3 hours, the substrate with the 3-TBAHFP/Nafion ${ }^{\circledR}$ layer was gently washed with water and analysed. The multiline laser ablation ( $n=4$ lines per each map; $c a$. $0.75 \mathrm{~mm}^{2}$ ) was performed on the surface of the samples with a constant speed (25 $\mu \mathrm{m} \mathrm{s}^{-1}$ ) followed by ICP-MS measurements. Transient signals were registered for the selected isotopes during each measurement cycle. The intensities of blank signals were registered for carrier gas (Ar) only and averaged for each isotope individually from the signals registered during $20 \mathrm{~s}$ before the start of ablation. The blank values were subtracted from the transient signals registered during the ablation of the samples. Spikes, defined as single raw intensity data higher than the mean of two neighboring data, were removed and replaced by the mean of the neighbouring values. The results obtained for the isotopes were recalculated to the equivalent of $1 \%$ abun-
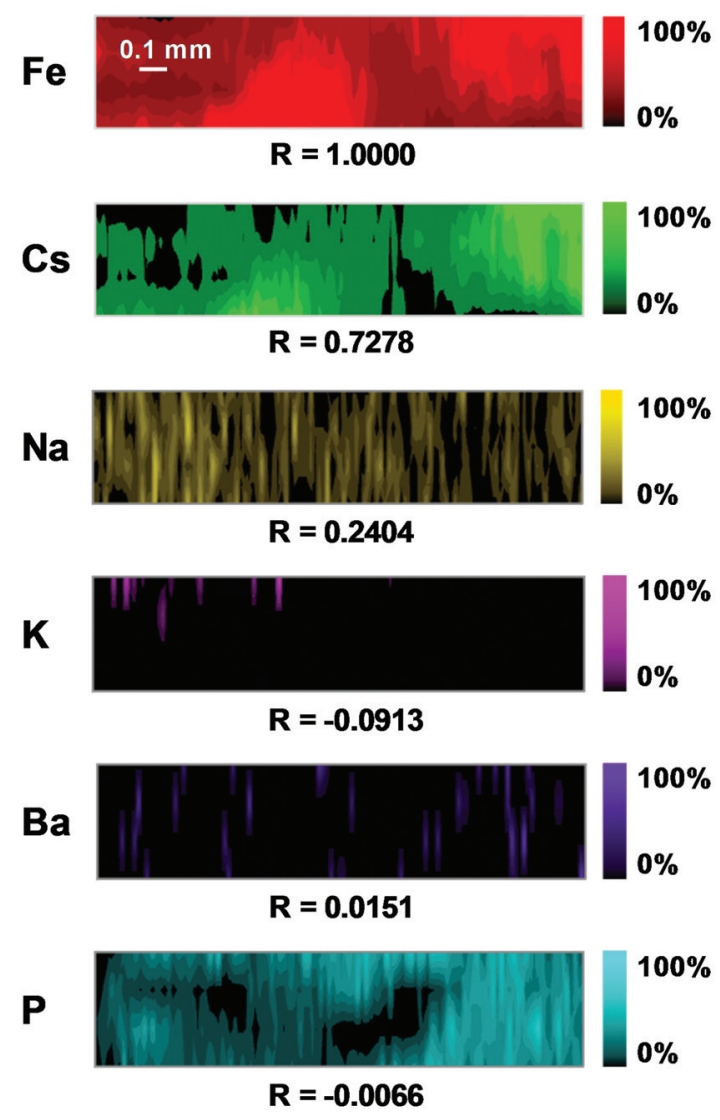

Fig. 7 Relative distribution maps reconstructed for the selected elements over the surface of the substrate. The Pearson correlation coefficients $\mathrm{R}$ between $\mathrm{Fe}$ and the given element signal intensities from the ablation area are listed below each element.

dance for each element and averaged from the 5 subsequent data. The registered signal intensities were independently recalculated for each monitored isotope with respect to the highest signal intensity (normalization to $100 \%$ ). The relative distribution patterns of $\mathrm{Fe}$ and $\mathrm{Cs}$ were evaluated for the electrodes before and after rinsing with mili-Q water (Fig. 7).

The correlation coefficient values were calculated and are given below the images of a particular element distribution to support the information about the co-presence of Fe and Cs relative to the other observed species $(\mathrm{Na}, \mathrm{P}, \mathrm{K}$, and $\mathrm{Ba})$. It should be noted that the presence of $\mathrm{P}$ is a consequence of using a supporting electrolyte, tetrabutylammonium hexafluorophosphate (TBAHFP), during the formation of the layer. It is clearly visible that although it is influenced by the heterogeneity of the electrode, still the correlation between the Fe and Cs distribution is much higher ( $\mathrm{R} \mathrm{ca}$. equal to 0.7 ) than that between the other elements. The averaged signal intensities are equivalent to $1 \%$. The abundance of each element was calculated to estimate the ratio between $\mathrm{Fe}$ and $\mathrm{Cs}$ which resulted in an approximated value of $10 \pm 4$. No exact quantification has been carried out, but based on this approach, a rough conclusion can be drawn about an order of magnitude greater content of Fe than that of Cs. 


\section{Conclusions}

In conclusion, 3, bearing a buckybowl motif, showed encouraging photophysical and electrochemical properties, which shed light on its prospective applications. In addition, 3 was used for the preparation of a $\mathrm{Cs}^{+}$-selective sensor. This is the first example of the construction of a buckybowl-based sensor, since in comparison with our previous work on sumanenylferrocenes for $\mathrm{Cs}^{+}$recognition in an organic solvent, ${ }^{7 b}$ here we constructed a reusable analytical device for the $\mathrm{Cs}^{+}$recognition in water. The $\mathrm{Cs}^{+}$detection in water was found to be highly selective and remarkably effective ( $\mathrm{LOD}=0.02 \mu \mathrm{M})$. The regeneration of the sensor is also easy to perform. We anticipate that this work will stimulate further progress in the chemistry and applications of metallocene-based buckybowls.

\section{Conflicts of interest}

There are no conflicts to declare.

\section{Acknowledgements}

Financial support from the Warsaw University of Technology is acknowledged. H. S. acknowledges the financial support by a Grant-in-Aid for Scientific Research on Innovative Area " $\pi$ Space Figuration" from MEXT (no. JP26102002), and JSPS KAKENHI (19H00912).

\section{Notes and references}

1 (a) D. Astruc, Eur. J. Inorg. Chem., 2017, 6-29; (b) K. Heinze and H. Lang, Organometallics, 2013, 32, 5623-5625.

2 (a) R. Sun, L. Wang, H. Yu, Z. ul-Abdin, Y. Chen, J. Huang and R. Tong, Organometallics, 2014, 33, 4560-4573; (b) A. Scozzari, in Algal Toxins: Nature, Occurrence, Effect and Detection, ed. V. Evangelista, L. Barsanti, A. M. Frassanito, V. Passarelli and P. Gualtieri, 2008; (c) O. B. Sutcliffe, A. Chesney and M. R. Bryce, J. Organomet. Chem., 2001, 637-639, 134-138; (d) N. G. Tsierkezos, J. Solution Chem., 2007, 36, 289-302; (e) A. Lewandowski, L. Waligora and M. Galinski, Electroanalysis, 2009, 21, 2221-2227.

3 (a) T. Romero, A. Caballero, A. Tarraga and P. Molina, Org. Lett., 2009, 11(15), 3466-3469; (b) L. Zhou, X.-T. Fan, Y.-D. Xu and Q.-Y. Cao, New J. Chem., 2015, 39, 8087-8092; (c) A. Kasprzak, K. Fateyeva, A. Kowalczyk and A. M. Nowicka, Anal. Chim. Acta, 2020, 1108, 10-20.

4 (a) L. Lvova, P. Galloni, B. Floris, I. Lundström, R. Paolesse and C. Di Natale, Sensors, 2013, 13, 5841-5856; (b) C. Bucher, C. H. Devillers, J.-C. Moutet, G. Royal and E. Saint-Aman, Chem. Rev., 2009, 253, 21-36.

5 M. S. Inkpen, S. Scheerer, M. Linseis, A. J. P. White, R. F. Winter, T. Albrecht and N. J. Long, Nat. Chem., 2016, 8, 825-830.
6 (a) H. Sakurai, T. Daiko and T. Hirao, Science, 2003, 301, 1878; (b) T. Amaya and T. Hirao, Chem. Rec., 2015, 15, 310321; (c) M. Saito, H. Shinokubo and H. Sakurai, Mater. Chem. Front., 2018, 2, 635-661; (d) S. N. Spisak, Z. Wei, A. Y. Rogachev, T. Amaya, T. Hirao and M. A. Petrukhina, Angew. Chem., Int. Ed., 2017, 56, 2582-2587; (e) H. Toda, Y. Uetake, Y. Yakiyama, H. Nakazawa, T. Kajitani, T. Fukushima and H. Sakurai, Synthesis, 2019, 4576-4581.

7 (a) B. Topolinski, B. M. Schmidt, S. Higashibayashi, H. Sakurai and D. Lentz, Dalton Trans., 2013, 42, 1380913812; (b) A. Kasprzak and H. Sakurai, Dalton Trans., 2019, 48, 17147-17152.

8 (a) D. Vijay, H. Sakurai, V. Subramanian and G. N. Sastry, Phys. Chem. Chem. Phys., 2012, 14, 3057-3065; (b) U. D. Priyakumar and G. N. Sastry, Tetrahedron Lett., 2003, 44, 6043-6046; (c) U. D. Priyakumar, M. G. P. Krishna and G. N. Sastry, Tetrahedron Lett., 2004, 60, 3037-3043.

9 (a) H. Kaeriyama, Fish. Oceanogr., 2017, 26, 99-113; (b) T. J. Yasunari, A. Stohl, R. S. Hayano, J. F. Burkhart, S. Eckhardt and T. Yasunari, Proc. Natl. Acad. Sci. U. S. A., 2011, 108, 19530-19534; (c) T. Mizuno and H. Kubo, Sci. Rep., 2013, 3, 1742; (d) Y. Masumoto, Y. Miyazawa, D. Tsumune, T. Tsubono, T. Kobayashi, H. Kawamura, C. Estournel, P. Marsaleix, L. Lanerolle, A. Mehra and Z. D. Garraffo, Elements, 2012, 8, 207-212.

10 T. Amaya, K. Mori, H.-L. Wu, S. Ishida, J.-i. Nakamura, K. Murata and T. Hirao, Chem. Commun., 2007, 1902-1904.

11 For the experimental details, see Experimental section (Section S1), ESI. $\dagger$

12 For the analytical data, see Sections S1-S6 in the ESI. $\dagger$

13 It was tracked with ${ }^{1} \mathrm{H}$ NMR. For the spectra, see Section S2, ESI. $\dagger$

$14 \lambda_{\max }$ for such derivatives was found to be between 278 and $485 \mathrm{~nm}$, see reference no. 10 .

15 The fluorescence intensity varied depending on the excitation wavelength $\left(\lambda_{\text {exc }}\right)$. The strongest fluorescence intensity with 3 was found for $\lambda_{\text {exc }}=530 \mathrm{~nm}$ (tested $\lambda_{\text {exc }}$ ranged between 330 and $510 \mathrm{~nm}$ ). Therefore, $\lambda_{\text {exc }}$ of $530 \mathrm{~nm}$ was used for the estimation of $\Phi_{\mathrm{F}}$ with 3.

16 This is a relative quantum yield in PhMe solution $\left(1 \times 10^{-6}\right.$ $\mathrm{M})$ with cresyl violet perchlorate as a standard. For details on estimating $\Phi_{\mathrm{F}}$, see Subsection S1.3, ESI. $\dagger$.

17 (a) S. Kunishige, M. Kawabata, M. Baba, T. Yamanaka, Y. Morita, S. Higashibayashi and H. Sakurai, J. Chem. Phys., 2013, 139, 044313; (b) B. B. Shrestha, S. Higashibayashi and H. Sakurai, Beilstein J. Org. Chem., 2014, 10, 841-847; (c) S. Hishikawa, Y. Okabe, R. Tsuruoka, S. Higashibayashi, H. Ohtsu, M. Kawano, Y. Yakiyama and H. Sakurai, Chem. Lett., 2017, 46, 1556-1559.

18 (a) R. Renner, M. Stolte and F. Würthner, ChemistryOpen, 2020, 9, e190029; (b) J. Mack, P. Vogel, D. Jones, N. Kavala and A. Suttona, Org. Biomol. Chem., 2007, 5, 2448-2452; (c) J. Dey, A. Y. Will, R. A. Agbaria, P. W. Rabideau, A. H. Abdourazak, R. Sygula and I. M. Warner, J. Fluoresc., 1997, 7, 231-236; (d) E. M. Muzammil, D. Halilovic and M. C. Stuparu, Commun. Chem., 2019, 2, 58; (e) X. Gu, 
X. Zhang, H. Ma, S. Jia, P. Zhang, Y. Zhao, Q. Liu, J. Wang, X. Zheng, J. W. Y. Lam, D. Ding and B. Z. Tang, Adv. Mater., 2018, 30, 1801065; (f) P. Liu, Y. Hisamune, M. D. Peeks, B. Odell, J. Q. Gong, L. M. Herz and H. L. Anderson, Angew. Chem., Int. Ed., 2016, 55, 8358-8362; (g) Y.-L. Wu, M. C. Stuparu, C. Boudon, J.-P. Gisselbrecht, W. B. Schweizer, K. K. Baldridge, J. S. Siegel and F. Diederich, J. Org. Chem., 2012, 77, 11014-11026.

19 (a) For the plots of the anodic peak heights as a function of the scan rate and square root of the scan rate, see Section S6, ESI; $\uparrow ;(b)$ For details on calculation of this diffusion coefficient, see Section S6, ESI. $\dagger$

20 N. S. Neghmouche and T. Lanez, Int. Lett. Chem., Phys. Astron., 2013, 4, 37-45.

21 (a) R. J. Forster and J. G. Vos, Macromolecules, 1990, 23, 4372; (b) A. J. Bard and L. R. Faulkner, Electrochemical methods: Fundamentals and Applications, Wiley, New York, 1980; $(c)$ linear regression equation is as follows: $I=(1.17 \pm$ $0.06) C_{\mathrm{Cs}}{ }^{+}+(102.9 \pm 1.3) \cdot R^{2}=0.993$.

22 (a) R. J. LeSuer and W. E. Geiger, Angew. Chem., Int. Ed., 2000, 39, 248-250, (Angew. Chem., 2000, 112, 254); (b) F. Barrière, N. Camine and W. E. Geiger, J. Am. Chem. Soc., 2002, 124, 7262-7263; (c) F. Barrière and W. E. Geiger, J. Am. Chem. Soc., 2006, 128, 3980-3989; (d) F. Barrière and W. E. Geiger, Acc. Chem. Res., 2010, 43, 1030-1039.
23 A. Yamauchi, K. Togami, A. M. Chaudry and A. M. El Sayed, J. Membr. Sci., 2005, 249, 119-126.

24 LOD was determined from the low concentration linearity range of the calibration curve according to the equation: $\mathrm{LOD}=3 \sigma \cdot a^{-1}$, where $\sigma$ is the standard deviation of the response and $a$ is the slope of the calibration curve.

25 (a) B. Radaram, T. Mako and M. Levine, Dalton Trans., 2013, 42, 16276-16278; (b) N. Kumar, Q. Pham-Xuan, A. Depauw, M. Hemadi, N.-T. Ha-Duong, J.-P. Lefevre, M.-H. Ha-Thi and I. Leray, New J. Chem., 2017, 41, 71627170; (c) V. Souchon, I. Leray and B. Valeur, Chem. Commun., 2006, 4224-4226; (d) X. Q. Pham, L. Jonusauskaite, A. Depauw, N. Kumar, J. P. Lefevre, A. Perrier, M.-H. Ha-Thi and I. Leray, J. Photochem. Photobiol., A, 2018, 364, 355-362; (e) E. Özcan and B. Çoşut, ChemistrySelect, 2018, 3, 7940-7944; (f) M. Arvand, M. Moghimi and M. A. Bagherinia, Anal. Lett., 2009, 42, 393-408.

26 This reference value in $\mathrm{mM}$ was estimated according to the data in $\mathrm{Bq} \mathrm{kg} \mathrm{kg}^{-1}$ presented in ref. $9 c$ and taking into account that $1000 \mathrm{mg}$ of $\mathrm{Cs}^{137}$ has an activity of $c a .3 .215 \times$ $10^{12} \mathrm{~Bq}$ (see: R. L. Bunting, Nucl. Data Sheets, 1975, 15, 335-369).

27 For data, see Section S5, ESI. $\dagger$ 